\title{
A natureza argumentativa dos processos inferenciais preditivos na compreensão textual
}

\author{
Tícia Cassiany Ferro Cavalcante \\ Selma Leitão \\ Universidade Federal de Pernambuco
}

\begin{abstract}
Resumo
No presente estudo, propõe-se que a inferência de predição é um processo cognitivo/discursivo de natureza eminentemente argumentativa. Partindo desta proposta teórica, o estudo empírico relatado teve como objetivo investigar, de forma processual, a produção de inferências preditivas por parte de sete estudantes universitários no curso de uma leitura individualmente realizada (compreensão online). A perspectiva metodológica adotada foi a do estudo de casos em série, em cada um dos quais o participante foi solicitado a responder, em voz audível, a questões formuladas à medida que lia uma crônica. A análise de dados realizada, de natureza notadamente qualitativa e processual, evidencia a natureza essencialmente argumentativa das inferências preditivas produzidas.
\end{abstract}

Palavras-chave: compreensão textual; inferência; argumentação.

\begin{abstract}
The argumentative nature of the predictive inferencial processes of the textual comprehension. The present study argues that a prediction inference is a cognitive/discursive process fundamentally of argumentative nature. From this theoretical premise, this empirical study investigated, in a procedural manner, the production of predictive inferences by seven university students, using individual readings (online comprehension). The methodology used was that of case studies in series, in each of which the participant was asked to answer, aloud, questions formulated while he/she was reading a story. The analysis of the data, notably of qualitative and procedural nature, makes evident the essentially argumentative nature of the predictive inferences produced.
\end{abstract}

Keywords: text comprehension; inference; argumentation.

$\mathrm{O}$ estudo reportado no presente artigo teve como objetivo investigar a natureza da inferência de predição, vista como processo cognitivo/discursivo que possibilita ao leitor predizer, ou antecipar, a continuação de um texto à medida que o lê. A hipótese investigada foi a de que tal modalidade de inferenciação teria natureza inerentemente argumentativa. $O$ processo inferencial de predição na compreensão textual e a argumentação são, portanto, os dois processos cognitivos/ discursivos aqui focalizados, entre os quais se propõe haver uma relação constitutiva.

O processo inferencial é foco central de discussão em estudos da compreensão textual (Oakhill \& Yuill, 1996; Perfetti, Marron, \& Foltz, 1996; Yuill \& Oakhill, 1991). É premissa praticamente consensual em estudos nessa área que a geração de inferências é condição necessária para que haja compreensão. Partindo dessa ideia, grande parte da pesquisa psicológica realizada nesse campo focaliza o funcionamento das habilidades inferenciais dos leitores (definidos como "competentes", ou "em formação") e os modos peculiares como aqueles, ao inferirem, integram informações presentes no texto (literais) com o seu conhecimento prévio (comumente referido como "conhecimento extratextual"). As bases teóricas subjacentes aos estudos da área - e, consequentemente, a concepção de sujeito-leitor que os orienta - remetem, majoritariamente, ao cognitivismo. Como mencionam Koch e Elias (2006), trata-se aí de um sujeito que constrói representações mentais do texto à medida que o lê, cabendo ao pesquisador investigar e compreender a natureza, produção e funcionamento dessas representações. Ao analisarem a compreensão textual, pesquisas da área utilizam-se, em geral, de dois procedimentos básicos: os que solicitam aos leitores que respondam questões após a leitura de um texto - e que, portanto, acessam apenas o produto final da compreensão - e os chamados procedimentos online - que se propõem a investigar a compreensão no curso da própria leitura.

O presente estudo parte, entretanto, de uma concepção distinta do sujeito-leitor e da natureza do processo de compreensão. Embora, à semelhança dos estudos de orientação cognitivista, também aqui se afirme a importância do processo inferencial na compreensão de texto, o presente estudo se distancia da concepção do leitor como sujeito individual, construtor de representações mentais que lhe permitem integrar informações do texto ao conhecimento estocado em sua memória 
de longo prazo e, assim, gerar inferências. Assume-se, em contraponto, que possibilidades de compreensão e hipóteses que o leitor elabora sobre a continuação do texto (inferências de predição) resultam de um processo de "negociação" entre múltiplas possibilidades de compreensão, que se constitui dialogicamente (no sentido bakhtiniano do termo). Em lugar da metáfora computacional (do acesso a conhecimento prévio estocado na mente do leitor), assume-se a metáfora do "diálogo". A dialogicidade é vista aqui como característica constitutiva da cognição humana (Linell, 2009; Markovà, 2003) - e, de resto, de processos psicológicos humanos - que possibilita ao leitor o engajamento num processo de negociação com diferentes "vozes" e discursos sociais (conhecimento prévio) os quais, mobilizados no ato da leitura, lhe permitem antecipar possibilidades variadas de continuação do texto. Sugere-se aqui que, ante as diversas hipóteses de continuação de texto que podem então surgir, necessário se faz uma "negociação" entre as alternativas consideradas com base na qual se possa estabelecer a maior ou menor plausibilidade de uma(s) sobre outra(s). Tal negociação caracterizaria a predição como uma atividade de natureza eminentemente dialógica.

Negociação e dialogia, nos sentidos acima indicados, são características igualmente inerentes à argumentação. A argumentação - em suas relações com a inferenciação - consiste no segundo processo cognitivo focalizado no presente estudo. A argumentação é aqui entendida como atividade de natureza discursiva e social que se caracteriza pela defesa de posições e a consideração de objeções e perspectivas alternativas, com o objetivo de aumentar, ou reduzir, a aceitabilidade de uma perspectiva (Leitão, 2007). Tomados conjuntamente, a concepção de inferência de predição como processo que demanda "negociação" (entre hipóteses de continuação de um texto) e o entendimento da argumentação como recurso discursivo que, por excelência, viabiliza a negociação de divergências constituem as premissas básicas em que fundamenta a tese central do presente estudo. Qual seja: a tese de que inferências de predição - em virtude do processo de negociação que lhes é inerente - são argumentativamente elaboradas.

Antes, porém, de informar detalhes do estudo empírico realizado, considerações são feitas sobre um conjunto de ideiaschave que subsidiaram o presente estudo - seja pela proximidade que se pode estabelecer entre aquelas e o que aqui é proposto, seja pelo distanciamento que delas se toma.

\section{Compreensão textual}

Como antes referido, em estudos realizados no marco cognitivista a compreensão textual é tipicamente conceituada como processo complexo que envolve aspectos cognitivos (memória de trabalho, conhecimento armazenado, monitoramento, integração de informações e inferências) e linguísticos (aspectos sintáticos, semânticos, lexicais e a habilidade de decodificação). A operação conjunta de fatores desta ordem permite, ao leitor, estabelecer conexões entre ideias explicitamente expressas no texto e seu conhecimento prévio (Oakhill \& Yuill, 1996; Perfetti et al., 1996; Yuill \& Oakhill, 1991) possibilitando-lhe assim a compreensão do que lê. Os aspectos cognitivos mencionados por tais estudos referem-se a processos que podem ser acessados através de atividades de linguagem - aí entendida como uma ferramenta pela qual se podem tornar explícitos os processos e conhecimentos armazenados na mente do indivíduo.

Diretamente relacionada a este entendimento da compreensão textual está a ideia genericamente aceita de que existe uma ligação entre o conteúdo literal do texto lido e o conhecimento prévio do leitor, conhecimento este caracterizado como conteúdo armazenado na memória e que deve ser acessado para que a compreensão se estabeleça. No ato da leitura, o leitor necessita não apenas extrair informações literais do texto, mas, principalmente, estabelecer relações entre o material linguístico dado no texto e seu conhecimento prévio. Para que essa integração aconteça, a inferenciação é essencial. A inferenciação caracteriza-se, portanto, como processo complexo que exige do leitor atividades de reflexão e a integração entre informações textuais (atuais) e conhecimentos prévios (Koch, 2003; Marcuschi, 1989).

O modelo teórico denominado de Construção-Integração (CI) de Kintsch (1998) tem, desde sua formulação, sido um dos principais inspiradores de estudos de base cognitivista. De acordo com o modelo CI, o processo de compreensão ocorreria em duas fases: a de construção e a de integração. Na primeira fase, representações mentais do texto são construídas localmente, de forma fragmentada (em partes). Já na fase de integração, o leitor estabelece limites e rejeita construções locais inapropriadas em favor daquelas que se integram em um todo coerente. Como destacam Andrade e Dias (2006), a fase de integração define-se como "uma bem estruturada representação mental" que "desativa as construções contextualmente não apropriadas” (p. 148). A integração é realizada assim que um novo elemento entra em cena na cadeia de representações em construção na mente do leitor; somente nesta fase é que o significado particular do texto se constrói em sua mente.

Um dos interesses principais dos estudos inspirados no modelo CI é a reflexão sobre dificuldades de compreensão que surgem em decorrência de inabilidades detectáveis nos processos cognitivos necessários à compreensão textual. Nota-se em tais estudos toda uma preocupação em entender o processo de inferenciação a partir da investigação dos processos psicológicos que estariam envolvidos na sua geração. No âmbito desses estudos definem-se como leitores habilidosos, ou maduros, àqueles que são capazes de gerar inferências, sendo categorizados como imaturos os que apresentam dificuldades na geração de inferências (Graesser, Wiemer-Hastings, \& WiemerHastings, 2001; Oakhill \& Garnham, 1988; Oakhill \& Yuill, 1996; Perfetti et al., 1996; Sanford \& Garrod, 1981).

Na literatura sobre compreensão textual, várias classificações coexistem sobre os tipos de inferências realizadas pelos indivíduos no ato da leitura (Kintsch, 1998; Marcuschi, 1989; Graesser, Singer, \& Trabasso, 1994; Sanford \& Garrod, 1981). Dentre os diferentes tipos descritos, incluem-se as inferências de predição, consideradas inerentes ao processo de compreensão textual - no curso do próprio processo de compreensão de um texto, o leitor realiza predições acerca da continuidade do mesmo. Para Solé (1998), a leitura é um processo constante de emissão e verificação de hipóteses (predições) que leva o leitor a construir uma compreensão do texto lido. Nesta perspectiva, 
a previsão que leitores maduros caracteristicamente realizam consiste em estabelecer hipóteses ajustadas e razoáveis sobre o que será encontrado no texto; para tanto, ancoram-se tanto na compreensão (em construção) do que já leram no textoalvo como em sua bagagem mais geral de conhecimentos e experiências. Num estudo recente sobre as inferências de predição, Spinillo e Mahon (2007) destacam como definidor da natureza particular dessas inferências o fato de que elas não só demandam a integração de partes do texto com informações extratextuais, mas, sobretudo, exigem a formulação de hipóteses sobre a continuidade do texto. É exatamente o pressuposto de que nas inferências de predição elaboram-se múltiplas possibilidades (hipóteses) de continuação textual que serve de ponto de partida para o presente estudo. Saliente-se, entretanto, que Spinillo e Mahon (2007) não se propuseram a investigar o processo que possibilita a construção de tais inferências, como foi o objetivo específico do presente estudo.

A despeito do grande número de estudos existente sobre inferências e compreensão textual, observa-se ainda (até onde se sabe) uma escassez de estudos que busquem investigar o próprio processo que possibilita sua construção. Este foi precisamente o objetivo pretendido aqui: investigar como se constituem as inferências de predição, entendendo-as como processo cognitivodiscursivo de natureza complexa e constitutivamente dialógico. Para tal, referências teóricas relevantes foram encontradas no quadro do dialogismo baktiniano.

\section{Compreensão como diálogo}

Perspectivas enunciativas de linguagem - o dialogismo bakhtiniano em particular - entendem o discurso como fenômeno intrinsecamente social, cujas produção e recepção (compreensão) ocorrem em situações históricas e esferas sociais específicas, que exercem sobre o discurso produzido/compreendido um papel determinante. Os discursos, sejam eles produzidos em modalidade oral, escrita ou gestual, materializam-se em gêneros e registros diversos, variações estas tidas como relevantes e adequadas às situações particulares em que são gerados. Nas palavras de Goulart (2009), a proposta central do pensamento bakhtiniano é estudar a enunciação enquanto tecido organizado e estruturado, que deve ser analisada em relação às condições específicas de sua produção.

Bakhtin (2002) enfatiza a natureza dialógica (relacional) das situações discursivas ao considerar que a enunciação se constitui como atividade responsiva (cada enunciado produzido responde a outro - ou outros - que o antecederam, ao mesmo tempo em que circunscreve suas possibilidades de continuação) e inerentemente avaliativa. $\mathrm{Na}$ interdiscursividade então constituída, os discursos dialogam entre si produzindo novos discursos; as muitas vozes sociais que os habitam se completam, polemizam entre si, respondem umas às outras (Goulart, 2009). A concepção de compreensão textual em que o presente estudo se ancora enfatiza a ação das vozes dialógicas que permeiam todo esse processo. A compreensão se constitui como elo de uma cadeia de relações dialógicas as quais permitem ao leitor voltar ao texto, procurar subsídios na situação contextual e, prospectiva e responsivamente, gerar antecipações (hipotetizar) acerca de sua continuidade.
Mesmo não priorizando a atividade de leitura em seus escritos, Bakhtin (2002) oferece uma perspectiva do que seria um processo de compreensão dialogicamente constituído e cujas nuances são capturáveis na oposição estabelecida entre compreensão passiva e ativa. A "compreensão passiva", afirma, não é capaz de comportar nem mesmo o esboço de uma resposta, como seria exigido por qualquer espécie autêntica de compreensão; por estar impregnada da compreensão da palavra em sua abstração, não possibilita o estabelecimento de uma compreensão propriamente dita (dialógica). Em contraste com esta (e o que de fato interessa para o autor), a "compreensão ativa" dos enunciados implica, sempre, uma tomada de posição do leitor sobre o que é dito/compreendido. Na compreensão ativa, múltiplos sentidos que podem ser derivados, mesmo que de uma única palavra, opõem-se uns aos outros e é somente no contexto situacional em que a palavra é produzida que o sentido desta ganhará determinação. Nos escritos do chamado Círculo de Bakhtin, compreender é necessariamente opor à enunciação do locutor uma contrapalavra, é uma ação responsiva que inevitavelmente carrega em si um acento de valor ou um tom apreciativo sobre o que é compreendido (Bakhtin, 2003).

É possível afirmar que a responsividade inerente à leitura a caracteriza como enunciação compartilhada e única, jamais repetida. Na dialogia característica da leitura, o leitor tanto avalia o ponto de vista do autor como, ao mesmo tempo, projeta e expõe seu ponto de vista (uma contrapalavra) à medida que, no curso da leitura, constrói sentidos para o texto. Como enfatiza Faraco (2003), a compreensão não é mera experienciação psicológica da ação de outros, mas, sim, uma atividade dialógica que, diante de um texto, permite ao leitor a construção de outro texto - o texto compreendido.

Como parte dessa compreensão ativa, o leitor elabora hipóteses de sentido defrontando-se, nesse processo, com possibilidades variadas de compreensão que se opõem entre si e o "convocam" a "optar" por alternativas que lhe pareçam mais coerentes. Numa perspectiva dialógica, parece-nos pertinente postular que ante as múltiplas - e nem sempre convergentes possibilidades de sentido que se abrem em relação a um texto, impõe-se uma espécie de "negociação" (atitude responsiva) entre as múltiplas e emaranhadas "vozes em jogo" no desencadeamento de inferências essenciais à compreensão textual.

\section{Argumentação e negociação}

Como assinalado na introdução deste trabalho, a argumentação é aqui conceituada como uma atividade de natureza discursiva que se constitui a partir da justificação de pontos de vistas e consideração e resposta a posições contrárias (contra-argumentos, em sentido lato), com o objetivo último de tornar as posições defendidas aceitáveis àqueles a quem a argumentação se dirige (Leitão, 2000; 2007; 2008). A justificação de pontos de vista e a consideração de ideias alternativas, tomadas em conjunto, criam, no discurso um espaço de negociação no qual perspectivas a respeito do mundo (físico ou social) são continuamente formuladas, revistas e transformadas. Leitão confere ao contra-argumento um papel crucial na argumentação. O contra-argumento "põe em xeque" um ponto de vista anteriormente proposto gerando-se, a partir 
daí, um processo dialógico de negociação (entre as perspectivas alternativas consideradas) que leva, inevitavelmente, à revisão do ponto de vista inicialmente formulado. Embora não assegure mudanças, este processo de revisão favorece o surgimento de novas perspectivas. De particular importância, no contexto do presente estudo, é a ideia de que a negociação é processo crucial à argumentação, visto que permite construção, avaliação e reconstrução de pontos de vista.

Com o objetivo de analisar os processos de revisão de perspectiva que ocorrem na argumentação, Leitão (2000) propôs uma unidade de análise triádica, composta de argumento, contra-argumento e resposta. $\mathrm{O}$ argumento é formado por ponto de vista e justificativa para o ponto de vista (podendo um destes elementos permanecer implícito no texto). O contraargumento, por sua vez, consiste em qualquer ideia, antecipada pelo próprio falante ou produzida por um interlocutor, que desafia um ponto de vista. O terceiro elemento, a resposta, define-se como a reação do proponente de um argumento a um contra-argumento surgido. A resposta é o elemento que permite capturar possíveis transformações no argumento inicialmente formulado, sendo ainda na resposta ao contra-argumento que o proponente do argumento expressa suas considerações favoráveis ou desfavoráveis sobre o ponto de vista em questão.

Em Leitão (2000), a resposta ao contra-argumento se configura de quatro formas, que implicam, ou não, ajustes na perspectiva (ponto de vista) assumida inicialmente pelo interlocutor. Numa primeira forma, o proponente de um ponto de vista destitui o contra-argumento, com a consequente preservação do argumento inicial. Na segunda, embora admita a plausibilidade do contra-argumento em questão, o proponente gera novas ideias que fortalecem seu argumento inicial, preservando-o, portanto, de sofrer modificação. A aceitação pelo menos parcial do argumentador com o contra-argumento é também característica da terceira forma de resposta, embora, desta feita, observe-se uma espécie de integração do conteúdo do contra-argumento à posição inicialmente formulada. $\mathrm{Na}$ última forma de resposta, diferentemente, a aceitação do contraargumento implica abandono da posição inicial do interlocutor, que assume nova posição.

\section{Argumentação e inferência}

Argumentar e inferir são processos intrinsecamente relacionados embora, tanto quanto se sabe, a natureza e especificidades dessa relação não seja ainda de todo compreendida. Esforços nesta direção podem, entretanto, ser identificados. Marcuschi (1996), por exemplo, de uma perspectiva aplicada, defende que o treinamento em argumentação e o desenvolvimento do raciocínio são essenciais no ensino da compreensão textual. Para o referido autor, a natureza dialética da argumentação - sua natureza intrinsecamente polêmica permitirá que os leitores reflitam sobre o conteúdo textual, possibilitando-lhes um trabalho com mais profundidade de todos os processos inferenciais envolvidos na compreensão. Com base nesta ideia se poderia talvez afirmar que a reflexão de Marcuschi (1996) insere-se numa linha de estudos que considera a argumentação propícia para o desencadeamento de reflexão (Candela, 1998; De Chiaro \& Leitão, 2005; Leitão, 2000; 2007).
Numa outra perspectiva, Pinto (2001) propõe que o argumento propicia o desencadeamento de inferências. Os argumentos são vistos pelo autor como convites à inferência - como convites, portanto, a formas de raciocínio já que a inferência é por ele considerada uma espécie de raciocínio. A produção de um argumento favorece a produção de inferências pelo interlocutor, não se tratando, portanto, a argumentação somente de uma atividade capaz de convencer o interlocutor da aceitabilidade do ponto de vista proposto. Apesar da ênfase no papel do argumento na elaboração e desencadeamento de inferências, Pinto parece valorizar a inferência em detrimento do argumento, sendo o último visto apenas como recurso linguístico capaz de favorecer o desencadeamento de inferências.

Num estudo atual em que tentam relacionar o inferir e o argumentar, Santa-Clara e Spinillo (2006) refletem sobre possíveis aproximações entre os dois processos, identificando (o que consideram) quatro pontos de convergência entre os dois processos, a saber: a presença, em ambos, de premissas e conclusões; a dependência de um e outro em relação a seus respectivos contextos de produção; a natureza dialógica de ambos; a previsão. Segundo as autoras, a previsão seria um dos pontos de contato entre o inferir e o argumentar, pois em ambos se faz previsões ao antecipar fatos. No argumentar, através, por exemplo, da antecipação a possíveis contra argumentos; já no inferir, pelas hipóteses elaboradas pelo leitor antes de realizar a leitura. Para as autoras, as previsões no inferir e no argumentar ilustram a permanente elaboração e reelaboração por parte de quem argumenta e de quem estabelece inferência. Embora as autoras proponham-se a refletir sobre possíveis aproximações entre argumentação e inferência através da identificação de pontos de contato entre os dois processos, o inferir e o argumentar são abordados como processos distintos, ou paralelos, não sendo sugerido em seu trabalho nenhum tipo de interdependência entre ambos.

Em contrapartida, a hipótese do presente estudo é a de que o processo inferencial de natureza preditiva é argumentativamente constituído. Sugere-se que a necessidade de uma "negociação" que possibilite a escolha de uma dentre diversas possibilidades de continuação de um texto levaria inevitavelmente à emergência de operações básicas da argumentação no plano do funcionamento cognitivo-discursivo do leitor.

\section{Método}

A pesquisa relatada em seguida se caracteriza como uma série de estudos de caso dos quais participaram sete estudantes do curso de graduação em Fonoaudiologia de uma universidade particular da cidade do Recife, com idades entre 20 e 23 anos.

A atividade proposta aos participantes foi a leitura de um texto sem intervenção direta da investigadora a qual permanecia na sala onde ocorria a leitura somente durante as instruções iniciais para a atividade. $\mathrm{O}$ texto em questão foi apresentado aos participantes num computador, com uso do programa PowerPoint, fonte 16, e segmentado em 40 partes. As segmentações foram feitas de modo a que cada segmento contivesse (critérios): a apresentação de uma ação inacabada, suscitando a sua finalização; a finalização de uma 
ação que permitia a avaliação do leitor, por envolver crenças e conhecimento prévios ou o surgimento de novos personagens e novos cenários.

Após cada segmento do texto ser apresentado, apareciam na tela, em slides separados, três perguntas que permitiam aos participantes explicitar diferentes aspectos do processo de compreensão textual (inferenciação) em andamento. Enquanto a primeira visava à produção de inferências de predição ("Qual será a continuação do texto?”), as segunda e terceira perguntas (“Como você chegou a essa idéia?" e "O que você está pensando?", respectivamente) contribuíam para a explicitação das bases constitutivas das inferências produzidas. As duas primeiras perguntas se repetiam, obrigatoriamente, após cada segmento do texto ser apresentado enquanto a terceira apenas surgia esporadicamente, sendo esta considerada uma pergunta alternativa e exploratória, utilizada para suscitar uma elaboração adicional das bases da inferência.

Aos participantes foi solicitado que realizassem a leitura do texto em voz alta e externalizassem seus pensamentos (thinkaloud protocol) - no caso, suas inferências - respondendo, igualmente em voz alta, às perguntas que iam aparecendo na tela. Toda a situação de leitura foi registrada em áudio e vídeo. $\mathrm{O}$ duplo registro se justificou pela expectativa de que, dessa forma, um maior número de elementos pudesse ser recuperado por ocasião da transcrição.

A escolha do texto utilizado no estudo foi realizada a partir de um critério básico: que o texto selecionado não pertencesse a um gênero saturado de sequências argumentativas. Este critério foi considerado crítico uma vez que não interessava ao estudo investigar inferências sobre argumentos porventura existentes no texto, mas, sim, processos argumentativos que - segundo a hipótese básica do estudo - seriam subjacentes à produção de inferências de predição relevantes à compreensão textual. Tal critério fez da escolha do texto-base uma tarefa complicada, uma vez que gêneros diversos tendem a ser altamente heterogêneos em relação aos tipos de discurso e sequências que entram em sua estrutura composicional.

Em Bronckart (1999), a noção de tipos de discurso remete aos diferentes segmentos ("formas de organização linguística", p. 250), presentes na estrutura composicional dos gêneros e que dão suporte a diferentes operações psico-linguageiras (um romance, por exemplo, pode conter tanto segmentos que dão conta da cronologia de fatos como segmentos de diálogo). Da planificação geral dos segmentos que compõem textos da ordem do argumentar fazem parte tipicamente (embora não necessariamente, adverte Bronckart, 2010) sequências verbais ("formas de planificação convencional", p. 250) constituídas por apresentação, sustentação e/ou refutação de teses. Sendo o ponto de partida do presente estudo a hipótese de que sequências dessa natureza estariam na base do processo inferencial (de predição) em que os participantes se engajariam durante a leitura de um texto, procurou-se, na escolha do texto que lhes seria apresentado, excluir a possibilidade de que sequências dessa natureza fossem já parte do gênero lido.

$\mathrm{O}$ texto finalmente selecionado intitulava-se A verdade (Veríssimo, 1984). O autor do texto é considerado pelos críticos um excelente humorista, criador de várias obras literárias, entre as quais incluem-se contos e crônicas. Para Marcuschi (1989), o referido texto, já utilizado com sucesso na investigação de processos inferenciais, permite, especificamente, desenvolver elementos básicos do imaginário popular dos leitores. Nele, fazem-se presentes diferentes valores: a família, o sexo, o crime, a moral, a diferença de classes sociais, dentre outros.

Para explorar a inferenciação, utilizou-se o teste de perguntas online, um dos procedimentos típicos em estudos da área (ver, por ex., Perfetti et al., 1996; Spinillo \& Mahon, 2007). Segundo Marcuschi (1989), existe uma longa tradição na utilização de teste com perguntas; todavia tais testes são usados, na maioria das vezes, na avaliação da compreensão offline - ou seja, a partir de perguntas que surgem após a leitura completa do texto. Diferentemente da compreensão offline, no teste de perguntas online solicita-se aos participantes que respondam a perguntas de compreensão durante a própria situação de leitura, caracterizando-se, portanto, como um procedimento no qual a compreensão é explicitada durante pausas na leitura, previamente estabelecidas pela pesquisadora. $\mathrm{O}$ teste de perguntas online com pausas preestabelecidas convida o leitor a refletir sobre sua compreensão no momento mesmo da leitura, permitindo-lhe que, ao retomá-la, após cada pausa, suas hipóteses e antecipações sobre a continuidade do texto sejam testadas.

Para tratamento dos dados obtidos no presente estudo, propôs-se uma unidade de análise constituída de duas partes que, conjuntamente tomadas, definiam os elementos mínimos que permitiriam capturar, microanaliticamente, o processo discursivo-argumentativo de construção de inferências de predição. Os elementos constitutivos da primeira parte da unidade de análise foram desenhados de modo a permitir identificar a produção de inferências de predição. São eles: 1-conteúdo textual (elemento deflagrador de todo o processo de inferenciação investigado) 2-pergunta deflagadora da predição (apresentada ao leitor após cada segmento textual: "Qual será a continuação do texto?”); 3-inferência de predição (construída em resposta à pergunta deflagadora da predição); 4-pergunta deflagadora de explicitação das bases da inferência ("Como você chegou a essa ideia?") seguida, ou não, de pergunta complementar (“O que você está pensando?"); 5-explicitação das bases constitutivas da inferência (em resposta à pergunta 2 , ou 2 e 3, acima). A segunda parte da unidade de análise, por sua vez, foi definida de modo a permitir a identificação da natureza argumentativa das predições realizadas. Foram utilizados para tanto os invariantes argumentativos propostos em Leitão (2000): (1) argumento (ponto de vista e justificativa); (2) contraargumento (entendido como qualquer elemento que levanta dúvidas, remete a alternativas, "põe em xeque" um argumento formulado) e (3) resposta ao contra-argumento.

\section{Resultados e discussão}

A título de ilustração do tratamento dado ao conjunto total dos dados gerados no estudo, a análise de um pequeno excerto do momento inicial de leitura de uma das participantes é apresentada a seguir. Com as análises procurou-se investigar a natureza das inferências de predição por meio da identificação de eventuais operações argumentativas presentes no curso do próprio processo 
de inferenciação. As operações argumentativas focalizadas foram a formulação de pontos de vista (hipóteses sobre a continuidade do texto), justificativa (explicitação de elementos geradores das hipóteses levantadas) e movimentos opositivos (dúvidas e consideração de hipóteses alternativas).

$\mathrm{Na}$ transcrição dos dados analisados, o sinal $(+)$ indica pausas da participante durante a leitura; parênteses duplos (( )) marcam comentários da pesquisadora; a letra $\mathrm{S}$, maiúscula, entre parênteses e seguida de número, identifica sequências discursivas produzidas pela participante; itálicos referem-se a marcadores discursivos que indicam a presença dos movimentos opositivos.

Em todas as situações de leituras analisadas, foi possível observar a produção tanto de inferências de predição baseadas em operações argumentativas dos tipos considerados na unidade de análise adotada no estudo. Uma vez que limitações de espaço impedem a apresentação do conjunto total das análises realizadas - ou mesmo da íntegra de um dos protocolos verbais gerados no estudo - optou-se aqui por trazer para o texto excertos dos dados de Milena (nome fictício). Com a microanálise apresentada em relação a cada um deles, acredita-se ser possível ilustrar o tratamento analítico aplicado ao conjunto dos dados. A opção pela apresentação dos dados de Milena deveu-se, sobretudo, à riqueza com que movimentos argumentativos foram produzidos e externalizados em suas falas durante o processo de compreensão textual gerado no estudo.

Milena

(S1): ((lendo excerto do texto exibido na tela)) a verdade (++) Uma donzela estava um dia sentada à beira de um riacho,

(S2): ((lendo pergunta deflagadora 1 na tela)) qual será a continuação do texto?

$(\mathrm{S} 3):(++)$ alguma coisa $(+)$ que aconteceu $(+)$ à beira do riacho (S4): ((lendo pergunta deflagadora 2 )) como você chegou a essa ideia?

(S5): $(++++)$ sei lá $(++)$ é $(++)$ porque eu acho assim se tá/ citou o lugar $(+)$ é porque $(+)$ alguma coisa de importante vai acontecer então lá ou então que $(+)$ vá dar sentido ao resto do texto

$\mathrm{Na}$ constituição da primeira inferência de predição identificada no excerto acima (S3 e S5) é já possível perceberse que Milena "dialoga" com múltiplas "vozes" para realizar antecipações acerca da continuidade do texto. Isto pode ser visto, por exemplo, quando toma o lugar mencionado em S1 (beira do riacho) como indicativo de que algum acontecimento relevante para a narrativa teria ali ocorrido. Tal comentário provavelmente remete a conhecimentos construídos por Milena, em suas participações anteriores em esferas sociais diversas, sobre a organização dos gêneros da ordem do narrar (Bronckart, 1999). Como bem sabido, gêneros dessa ordem são amplamente produzidos em toda uma gama de situações cotidianas - e de modo especial, nas práticas discursivas que ocorrem na escola nos primeiros anos de escolaridade. Conhecimentos adquiridos nessas esferas sociais (de modo frequentemente indireto e implícito) permitem ao leitor de uma narrativa ficcional (Milena, por exemplo) inferir, preditivamente, a partir de um cenário que se anuncia/enuncia, que alguma ação será em seguida introduzida na cena narrativa ("alguma coisa $(+)$ que aconteceu $(+)$ à beira do riacho"). É característico da composição de variados gêneros narrativos (ficcionais, ou não) que um cenário seja descrito sempre que uma trama relevante à narrativa em questão é nele desenvolvida, como também que à introdução de personagens centrais siga-se uma descrição de suas ações e/ou de ações de outros em relação àqueles (Adam, 1992; Bronckart, 1999). É possível afirmar, portanto, que o tipo de inferência realizada em S3 remete a (e depende de) conhecimentos sociais previamente adquiridos que definem a ação dos personagens como um dos constituintes básicos na organização do gênero lido.

Três aspectos, pelo menos, podem ser destacados na análise do movimento inferencial acima. Em primeiro lugar, que conhecimentos acerca de características de gênero são inevitavelmente convocados em meio à dialogicidade estabelecida entre o leitor e vozes sociais diversas que constituem o texto a que o mesmo é exposto no ato da leitura. Segundo, que os sentidos produzidos para o texto (no caso, por Milena) resultam do diálogo que se estabelece, não somente com as vozes presentes no texto atualmente lido, mas, também, com todo um emaranhado de vozes constitutivas de textos anteriormente lidos que "informam" o leitor tanto sobre possibilidades de continuação do texto bem como sobre restrições (semânticas, contextuais) que o enunciado já lido (S1) impõe à continuidade do texto - em outras palavras, informam, sobre a natureza do que pode ser dito em seguida. Em terceiro e último lugar, aos propósitos do presente artigo interessa acima de tudo destacar que o processo que possibilita a produção de inferências de predição apontado em S3 é argumentativamente constituído. É para esse aspecto da análise que os parágrafos seguintes se voltam.

A inferência em S3 adquire na fala de Milena o status de um ponto de vista, a consideração de uma possibilidade (dentre outras possíveis) acerca da continuação do texto. $\mathrm{O}$ caminho que afirma ter percorrido para formular essa predição é argumentativamente constituído, expresso e linguisticamente marcado ("porque") na forma de uma justificativa (um apoio) para o ponto de vista proposto (S5: "porque eu acho assim se tá/ citou o lugar $(+)$ é porque $(+)$ alguma coisa de importante vai acontecer então lá ou então que $(+)$ vá dar sentido ao resto do texto"). Enquanto o porque com que se inicia S5 poderia ser considerado como uma forma linguística talvez provocada pela pergunta em S4 (“como chegou a essa ideia?"), o segundo porque marca claramente o raciocínio condicional em que Milena apoia em sua inferência. Na justificativa produzida, conteúdos textuais recuperados em S1 ("o lugar") e conhecimentos sociais concernentes aos gêneros narrativos ficcionais ("alguma coisa vai acontecer") integram-se mais uma vez. Adicionalmente, a elaboração de uma justificativa para o ponto de vista antes formulado reflete ainda a preocupação da participante com os sentidos que são constituídos nos textos; seu comentário em S5 reflete e mobiliza o conhecimento de que um texto precisa ter sentido para que cumpra a finalidade para a qual foi produzido ("ou então que $(+)$ vá dar sentido ao resto do texto").

Ainda em S5, movimentos opositivos identificáveis em dois momentos nos parecem ratificar a tese básica do presente trabalho, qual seja, de que inferências de predição são inerentemente argumentativas. $\mathrm{O}$ primeiro desses movimentos 
opositivos é analiticamente identificado no emprego do marcador discursivo ACHO ("porque eu acho assim"), verbo que marca uma atitude proposicional, uma tomada de posição que deixa em aberto outras possibilidades de continuação do texto. O posicionamento assumido a partir do "eu acho" deixa em aberto a possibilidade de que outras vozes (outros dizeres) surjam no texto que venham a enfraquecer o argumento inicial da participante (a predição proposta em S3). Com uma escolha lexical, a participante marca a existência de outras possibilidades de continuação textual e, ao fazê-lo, cria já, por si só, um efeito contra-argumentativo, um potencial enfraquecimento da predição (argumento) anteriormente formulada. O emprego do (eu) acho marca a aceitação de Milena de que seu ponto de vista não é o único defensável instaurando a dúvida sobre a continuação do texto - o que afirma trata-se tão somente de um ponto de vista, uma hipótese por ela elaborada.

O segundo movimento opositivo identificado no excerto acima é observável quando da enunciação de um outro operador argumentativo: ou então. À semelhança do caso acima discutido, o uso desse operador marca a natureza argumentativa do processo de constituição da inferência de predição à medida que introduz argumentos alternativos - possibilidades alternativas de continuação do texto.

(S6): ((lendo excerto do texto exibido na tela)) deixando a água do riacho passar por entre seus dedos muito brancos quando (S7): ((lendo pergunta deflagadora 1)) qual será a continuação do texto?

$(\mathrm{S} 8)$ : $(+)$ aconteceu alguma coisa $(+)$ que é relevante pro texto $(+)$ pro sentido do texto

(S9): ((lendo pergunta deflagadora 2)) como você chegou a essa ideia?

(S10): $(+)$ dedução $(+)$ pra dar continuidade ao texto tem que ter $(+)$ seguimento

Como no excerto antes analisado, a inferência de predição que aparece em S8 (“) (+) aconteceu alguma coisa $(+)$ que é relevante pro texto $(+)$ pro sentido do texto”) toma a forma de um ponto de vista na construção do qual se pode considerar a participação de conhecimentos anteriormente adquiridos. Uma vez mais, a fala de Milena em S10 nos parece remeter a conhecimentos mais globais, relativos à produção/compreensão de gêneros narrativos: a relevância da sequenciação, da coerência, de organizadores específicos do gênero lido. A presença do modalizador "tem que" (= é necessário) constrói como necessário ao gênero lido uma organização temporal de eventos (o "texto tem que ter $(+)$ seguimento), eventos esses que Milena se esforça por antecipar (“ (+) aconteceu alguma coisa $(+)$ que é relevante pro texto $(+)$ pro sentido do texto"). É, portanto, do diálogo estabelecido entre vozes inerentes ao texto e ao contexto em que se dá a leitura, que resultam uma vez mais os elementos que "autorizam" a leitora a realizar suas predições.

Os elementos em que busca apoio para o ponto de vista (predição) formulado em S8 (" $(+)$ aconteceu alguma coisa $(+)$ que é relevante $(+)$ pro sentido do texto") são formulados em S10: ("dedução $(+)$ pra dar continuidade ao texto tem que ter $(+)$ seguimento"). Do ponto de vista argumentativo, a verbalização em S10 assume a função de uma justificativa, relativa ao ponto de vista proposto.

\section{Considerações finais}

Como destaca Solé (1998), a leitura de um texto escrito pode ser caracterizada como um processo de constante emissão e verificação de hipóteses que levam o leitor à construir uma compreensão, um sentido para o texto. Nesta perspectiva conceitual, o estudo do processo de inferenciação preditiva assume lugar de particular relevância, uma vez que dele depende a formulação de hipóteses/antecipações sobre a continuidade do texto.

Tradicionalmente, processos de inferenciação têm sido estudados numa perspectiva cognitivista com base na qual um corpo - indiscutivelmente relevante - de conhecimento vem sendo construído sobre as relações entre inferência e compreensão textual. A adoção de uma perspectiva teórica diversa - no caso, uma concepção discursiva da cognição (Edwards, 1997; Harré \& Gillett, 1999) - permitiu, entretanto, que se investigasse, no presente estudo, um aspecto do processo de inferenciação dificilmente capturável em estudos que partem de uma perspectiva cognitivista do processo da leitura, qual seja: a dimensão inerentemente argumentativo-discursiva das inferências preditivas.

A idéia central sugerida ao longo do presente texto é que inferências de predição poderiam ser vistas como conclusões de argumentos, na formulação dos quais toda uma gama de elementos (textuais/extratextuais) disponíveis na situação de leitura assume a função retórica de justificativas (fundamento, apoio), relativas às predições que o leitor realiza. Considerase também teoricamente sustentável a afirmativa de que a formulação de pontos de vistas e o estabelecimento de conclusões sobre sentido e continuidade do texto ocorrem, necessariamente, contra o pano de fundo de hipóteses alternativas - possibilidades outras de entendimento daquele. $\mathrm{Na}$ concepção dialógicodialética de argumentação em que se ancora o presente estudo, a consideração de possibilidades alternativas é teoricamente conceituada como uma ação discursiva de oposição (contraargumentação), ação esta que funda os funcionamentos argumentativos de pensamento. Ações discursivas de oposição instauram a dúvida nas hipóteses de compreensão formuladas no curso da leitura e, ao fazê-lo, permitem que o leitor realize ajustamentos em hipóteses anteriormente elaboradas considerando, portanto, variadas perspectivas de entendimento do texto.

Considera-se, ainda, que todo este movimento de elaboração de hipóteses de continuação do texto (confirmadas, refutadas ou ajustadas no curso da leitura) pode ser teoricamente descrito como um processo argumentativo de negociação. Segundo Leitão (2000; 2007), a justificação de pontos de vista e a consideração de idéias alternativas, tomadas em conjunto, criam, no discurso um espaço de negociação no qual perspectivas são continuamente formuladas, revistas e transformadas. A existência de uma negociação de alternativas, no centro mesmo do processo discursivo que possibilita a inferência preditiva, confere, portanto, a este tipo de processo de raciocínio uma 
natureza eminentemente argumentativa.

Os aspectos apontados na microanálise dos excertos acima (representativos da análise realizada no corpus construído) nos parecem oferecer apoio empírico à tese proposta. Com base nas análises realizadas é possível afirmar que a participante - uma "leitora proficiente" (no sentido cognitivista do termo presente em Oakhill \& Yuill, 1996; Perfetti et al., 1996; Yuill \& Oakhill, 1991) - mobiliza, dialógica e argumentativamente, tanto elementos disponíveis de imediato na superfície do texto lido (textuais num sentido mais estrito) como elementos relativos a um campo mais amplo de conhecimento (contextuais) os quais, conjuntamente, informam as predições que realiza. As análises apresentadas permitiram identificar a emergência de diferentes operações argumentativas como parte de, e no curso mesmo do processo de geração de inferências de predição. Tais análises permitem, portanto, descrever, empiricamente, a natureza argumentativa da inferência de predição.

\section{Referências}

Adam, J. M. (1992). Les textes: types et prototypes. Paris: Nathan.

Andrade, M. W. C. L., \& Dias, M. G. B. B. (2006). Processos que levam à compreensão de textos. Psicologia em Estudo, 11(1), 147-154

Bakhtin, M. (2002). Marxismo e filosofia da linguagem. São Paulo: Hucitec. Bakhtin, M. (2003). Estética da criação verbal. São Paulo: Martins Fontes.

Bronckart, J. P. (1999). Atividade de linguagem, textos e discursos: por um interacionismo sócio-discursivo. São Paulo: EPUC.

Bronckart, J. P. (2010). Gêneros de textos, tipos de discurso e sequências. Por uma renovação do ensino da produção escrita. Conferência proferida na Pontifícia Universidade Católica de São Paulo, São Paulo.

Candela, A. (1998). Construção discursiva de contextos argumentativos no ensino de ciências. In C. Coll \& D. Edwards (Orgs.), Ensino, aprendizagem e discurso em sala de aula: aproximações ao estudo do discurso educacional (pp. 143-169). Porto Alegre: Artes Médicas.

De Chiaro, S., \& Leitão, S. (2005). O papel do professor na construção discursiva da argumentação em sala de aula. Psicologia: reflexão e crítica, 18(3), 350-357.

Edwards, D. (1997). Discourse and cognition. Londres: Sage.

Faraco, C. A. (2003). Linguagem e diálogo. As ideias linguísticas do círculo de Bakhtin. Curitiba: Criar.

Goulart, C. (2009). Em busca de balizadores para análise de interações discursivas em sala de aula com base em Bakhtin. Revista de Educação Pública, 18(36), 15-31.

Graesser, A. C., Singer, M \& Trabasso, T. (1994). Constructing inferences during narrative text comprehension. Psychological Review, 101(3), 371-195.

Graesser, A. C., Wiemer-Hasting, P., \& Wiemer-Hasting, K. (2001). Constructing inferences and relations during text comprehension. In T. Sanders, J. Schilperoord \& W. Spooren (Orgs.), Text representation. Linguistic and psycholinguistic aspects (pp. 271-395). Amsterdam: John Benjamins.

Harré, R., \& Gillett, G. (1999). A mente discursiva: os avanços da ciência cognitiva. Porto Alegre: Artes Médicas.

Kintsch, W. (1998). Comprehension: a paradigm for cognition. Cambridge: Cambridge University Press.

Koch, I. G. V. (2003). Argumentação e linguagem. São Paulo: Cortez.

Koch, I. G. V., \& Elias, V. M. (2006). Ler e compreender. os sentidos do texto. São Paulo: Contexto.

Leitão, S. (2000). The potential of argument in knowledge building. Human Development, 6, 332-360

Leitão, S. (2007). Argumentação e desenvolvimento do pensamento reflexivo. Psicologia: Reflexão e Crítica, 2(3), 454-462.

Leitão, S. (2008). La dimensión epistémica de la argumentación. In E. Kronmüller \& C. Cornejo (Orgs), Ciencias de la mente: Aproximaciones desde Latinoamérica, (pp. 89-119). Santiago: JCSáez.

Linell, P. (2009). Rethinking language, mind, and world dialogically: interactional and contextual theories of human sense-making. Charlotte, NC: Information Age.

Marcuschi, L. A. (1989). O processo inferencial na compreensão de textos. (Relatório final apresentado ao CNPq, Programa de Pós-graduação em Letras e Linguística, Universidade Federal de Pernambuco, Recife).

Marcuschi, L. A. (1996). Exercícios de compreensão ou copiação nos manuais de ensino da língua? Em Aberto, 16 (69), 63-82.

Markovà, I. (2003). Dialogicidade e representações sociais: as dinâmicas da mente. Petrópolis: Vozes.

Oakhill, J., \& Garnham, A. (1988). Becoming a skilled reader. Nova Iorque: Basil Blackwell.

Oakhill, J., \& Yuill, N. (1996). Higher order factors in comprehension disability: processes and remediation. In C. Cornoldi \& J. Oakhill (Orgs.), Reading comprehension difficulties - processes and intervention (pp. 69-92). Mahwah: Lawrence Erlbaum.

Perfetti, C. A., Marron, M. A., \& Foltz, P. W. (1996). Sources of comprehension failure: theoretical perspective and case studies. In C. Cornoldi \& J. Oakhill (Orgs.), Reading comprehension difficulties - processes and intervention (pp. 137-165). Mahwah: Lawrence Erlbaum.

Pinto, R. C. (2001). Argument, inference and dialectic. Boston: Kluwer Academic.

Sanford, A. J., \& Garrod, S. C. (1981). Understanding written language: explorations of comprehension beyond the sentence. Nova Iorque: John Wiley \& Sons.

Santa-Clara, A., \& Spinillo, A. G. (2006). Pontos de convergência entre o inferir e o argumentar. Psicologia: Teoria e Pesquisa, 22(1), 87-94.

Solé, I. (1998). Estratégias de leitura. Porto Alegre: Artmed.

Spinillo, A. G., \& Mahon, E. R. (2007). Compreensão de texto em crianças: comparação entre diferentes classes de inferências a partir de uma metodologia on-line. Psicologia Reflexão e Crítica, 20(3), 463-471.

Veríssimo, L. F. (1984). A Mulher do Silva. Porto Alegre: L\&PM

Yuill, N., \& Oakhill, J. (1991). Children's problems in text comprehension: an experimental investigation. Cambridge, Inglaterra: Cambridge University Press.

Tícia Cassiany Ferro Cavalcante, doutora em Psicologia Cognitiva pela Universidade Federal de Pernambuco, é professora Adjunta na Universidade Federal de Pernambuco. Endereço para correspondência: Universidade Federal de Pernambuco, Centro de Educação, Departamento de Psicologia e Orientação Educacionais. Avenida da Arquitetura, S/N., Cidade Universitária, Recife, PE. CEP:50740-550. Fone/fax: 2126-8323. E-mail: ticiaferro@hotmail.com

Selma Leitão, doutora em Psicologia Cognitiva pela University of Cambridge, e Pós-doutorado pela Clark University, é professor Adjunto na Universidade Federal de Pernambuco UFPE. E-mail: selma_leitao2001@ yahoo.com 